\title{
The significance of Agaricus blazei as an immunomodulator of the level of IL-17 in Balb/C mice with atherosclerosis
}

\author{
DICKY KURNIAWAN TONTOWIPUTRO ${ }^{I}$, DJANGGAN SARGOWO ${ }^{I}$, \\ ASKANDAR TJOKROPRAWIRO ${ }^{\prime}$, MUHAIMIN RIFA'I \\ 'Biomedical Department, Medical Faculty, University of Brawijaya, Malang, Indonesia \\ ${ }^{2}$ Biology Department, Faculty of Mathematics and Natural Sciences, University of Brawijaya, Malang, Indonesia
}

\begin{abstract}
Atherosclerosis is a disease caused by an inflammatory response which involved the interaction between endothelial cells, macrophages and lymphocytes, and is closely related to IL-17 regulation. This study is important to investigate the activity of Agaricus blazei in modulating the immunological activity based on the profile of $C D 4^{+} I L-17^{+}, C D 8^{+} I L-17^{+}$, and $C D 11 b^{+} I L-17^{+}$in high-fat diet (HFD)induced Balb/c mice. Mice in dietary groups were fed with HFD and then fed with A. blazei extract with three different doses including D1 (100 mg/kg BW), D2 (200 mg/kg BW), and D3 (400 mg/kg BW) once a day for 12 weeks. The cells were analyzed using flow cytometry and tested statistically with one-way ANOVA with $\alpha=0.05$ by using SPSS 16.00 software. The results showed that mice with HFD treatment had a higher level of Lp-PLA2 (atherosclerosis marker) compared with the control group (data not shown). The level of IL-17 in the atherosclerotic mice in the D1 group was significantly depleted compared to the control group. Of the three doses above, D1 may be an optimal dose to minimize or prevent the damage from atherosclerosis than the other doses.
\end{abstract}

Key words: inflammation, atherosclerosis, high-fat diet, immunomodulator, Agaricus blazei.

(Centr Eur J Immunol 2020; 45 (1): 1-8)

\section{Introduction}

Atherosclerosis is a multifactorial process involving interactions between endothelial cells, macrophages, and lymphocytes which is characterized by deposits of mass collagen, cholesterol, cell waste products and calcium, along with the proliferation of myocytes. This may progress by thickening and hardening of artery walls which caused stiffness and the fragility of the arteries $[1,2]$. The inflammatory reaction in atherosclerosis is characterized by extra-cellular lipid accumulation recruitment and migration of myocytes, foam cell formation and deposit of extracellular matrix [3].

Atherosclerosis is strongly influenced by high cholesterol (especially LDL), smoking, high blood pressure, diabetes mellitus, obesity, and lack of physical activity. Monocytes will differentiate into macrophages and eliminate the oxidized LDL (ox-LDL) and form foam cells and secrete proinflammatory cytokines which will increase the occurrence of atherosclerosis. T lymphocyte cells become active and stimulated to produce proinflammatory cytokines. Immune cells such as macrophages, natural killer (NK) cells, smooth muscle cells (SMC) and other immune cells also become ac- tivated and produce other proinflammatory cytokines which accelerate the formation of atherosclerosis $[4,5]$.

It has been known that proinflammatory cytokines which play a role in atherogenesis are interleukin (IL)-1 and tumor necrosis factor $\alpha(\mathrm{TNF}-\alpha)$. But some studies had identified that IL-17 appeared to be closely linked in the pathogenesis of atherosclerosis and change the paradigm of Th1/Th2 [6]. The expression of cytokine IL-17 is influenced by regulatory T cells (Treg) which is important to maintain the homeostasis of the subset of cells involved in adaptive immunity by releasing anti-inflammatory cytokine, IL-10, and transforming growth factor $\beta$ (TGF- $\beta$ ) [7].

Agaricus blazei is a widely used edible mushroom which produces various bioactive compounds such as polysaccharides, proteoglycans, terpenoids, phenolic compounds, steroids, and lectins. The polysaccharide mixture in A. blazei has a benefit on the cardiovascular system either directly or indirectly. A mixture of polysaccharides which has been proven to have a benefit on the cardiovascular system, namely glucan (especially $\beta$-glucan) and protein-bound polysaccharides [8-11]. Those compounds play a critical role in therapeutic effects and may act as immune-modulatory, anticarcinogenic, antiviral, antioxi-

Correspondence: Dicky Kurniawan Tontowiputro, MD, Biomedical Department, Medical Faculty, University of Brawijaya, Jalan Veteran Malang, 65145 East Java, Indonesia, e-mail: kurniawan.dicky27@gmail.com Submitted: 29.04.2017; Accepted: 9.06.2017 
dant, and anti-inflammatory agents. The present study was designed to investigate the protective effect of A. blazei on IL-17 production in Balb/c mice with high-fat diet (HFD).

\section{Material and methods}

This study was conducted at the Animal Physiology Laboratory, University of Brawijaya. The study was carried out between August 2016 and December 2016. Completely random factorial experiments were conducted with four replications in 6 groups: the healthy control group, the positive control group (mice with HFD), the HFD group followed by A. blazei administration with 3 different doses including D1 (100 mg/kg BW), D2 (200 mg/kg BW), and D3 (400 mg/kg BW).

\section{Experimental diets and animal treatment}

A standard feed for the healthy group consisted of $66.6 \%$ of chicken feed/PARS (with a content of water, protein, fat, fiber, ash, $\mathrm{Ca}$, phosphorus, antibiotics, coccidiostat) and 33.4\% of wheat flour. While the HFD consisted of standard feed $57.3 \%$ of chicken feed/PARS and 31.8\% of wheat flour) plus $10 \%$ of goat fat, $10 \%$ of lard, $5 \%$ of yolk, $1 \%$ of coconut oil, and $0.1 \%$ of cholic acid.

The in vivo experiment was conducted on 8-weekold Balb/c mice (weighing at least $25 \mathrm{~g}$ ) purchased from Gadjah Mada University, Yogyakarta, and maintained in pathogen-free facility and fed ad libitum. After two weeks of the adaptation period, mice in dietary groups were fed with HFD and then fed with A. blazei extract with three different doses including D1 (100 mg/kg BW), D2 (200 mg/kg BW), and D3 (400 mg/kg BW) once a day for 12 weeks. The experimental protocol was approved by Ethical Clearance from the Research Ethics Committee (Animal Care and Use Committee) of University of Brawijaya No. 335/EC/KEPK-S3/09/2016.

\section{Lymphocyte isolation}

After 12 weeks of the feeding period, mice were sacrificed using the dislocation method. Spleen was isolated and pressed clockwise with the syringe base. Aggregates were separated by gentle pipetting, and debris was discarded by passaging the suspension through a cell strainer (100- $\mu$ m nylon). The suspension in propylene was added with PBS up to $10 \mathrm{ml}$ and were then centrifuged at $1500 \mathrm{rpm}, 4^{\circ} \mathrm{C}$ for 5 minutes.

\section{Intracellular staining and flow cytometry analysis}

The combinations of the antibody for intracellular staining was FITC-conjugated rat anti-mouse CD4, FITC-conjugated rat anti-mouse CD11b, PE-conjugated rat anti-mouse $\mathrm{CD} 8$ and $\mathrm{PE} / \mathrm{Cy} 5$-conjugated rat anti-mouse IL-17. The obtained cells were incubated with extracel- lular antibodies for $20 \mathrm{~min}$ in the ice box at $4^{\circ} \mathrm{C}$. After incubation, the suspension was washed and the pellet was resuspended in cytofix buffer $(50 \mu \mathrm{l})$ for $20 \mathrm{~min}$ in dark conditions at $4^{\circ} \mathrm{C}$. Then the suspension was resuspended in $500 \mu \mathrm{l}$ wash-perm and centrifuged at $2500 \mathrm{rpm}, 10^{\circ} \mathrm{C}$ for $5 \mathrm{~min}$. Supernatant was discarded and the obtained pellet was subjected to intracellular staining for $20 \mathrm{~min}$, at $4{ }^{\circ} \mathrm{C}$. Each sample was transferred into a flow cytometry cuvette and then analyzed with a flow cytometer (FACSCalibur; BD Biosciences, New Jersey, USA), and calculated using BD CellQuest PRO software.

\section{Statistical analysis}

One-way ANOVA was used to analyze the data. The differences between groups were considered significant at $p<0.05$. All results were presented as the mean of $\pm \mathrm{SD}$ values of 3 mice in each group. This was followed by a post-hoc Tukey's honestly significant difference (HSD) test to determine major changes and differences among the $\mathrm{CD} 4^{+} \mathrm{IL}-17^{+}, \mathrm{CD} 8{ }^{+} \mathrm{IL}-17^{+}$, and $\mathrm{CD} 11 \mathrm{~b}^{+} \mathrm{IL}-17^{+}$cells relative to the density mean values.

\section{Results}

\section{Agaricus blazei is able to inhibit the expression of IL-17 on T lymphocyte}

The expression of IL-17 is widely used as a marker of inflammation especially in atherosclerosis and arthritis. IL-17 is expressed by several cells, including Th17 cells, monocytes, neutrophils, and NK cells [16]. As the cells which mostly produce IL-17 are Th17 cells, thus the IL-17 producing cells have been primarily used for determining the role of IL-17 in atherosclerosis development. Examination of IL-17 expression in Balb/c mice with HFD showed a marked increase compared to healthy controls $(4.85 \%$ vs. $3.13 \%)$. Furthermore, the number of CD $4^{+} \mathrm{IL}-17^{+}$after treatment with A. blazei at a dose of $100 \mathrm{mg} / \mathrm{kg} \mathrm{BW}$ for 12 weeks was significantly decreased compared to the HFD group (2.38\% vs. $4.85 \%$ ). According to the obtained result, the lowest dose of $A$. blazei was considered as the effective dose to decrease the level of IL-17 compared to the other doses. However, no significant difference was found in the level of CD4 $4^{+} \mathrm{IL}-17^{+}$of the D2 and D3 group compared to the healthy control group $(4.98 \%$ vs. $4.85 \%$ and $4.00 \%$ vs. $4.85 \%$ ) (Fig. 1).

Figure 2 shows that the expression of $\mathrm{CD} 8^{+} \mathrm{IL}-17^{+}$in Balb/c mice with HFD was significantly increased compared to the healthy control group ( $11.61 \%$ vs. $1.83 \%)$. Furthermore, the level of $\mathrm{CD} 8{ }^{+} \mathrm{IL}-17^{+}$after $A$. blazei treatment at a dose of $100 \mathrm{mg} / \mathrm{kg} \mathrm{BW}$ for 12 weeks showed a marked decrease compared to the HFD treatment $(5.24 \%$ vs. $11.24 \%)$. On the other hand, the level of CD8 $8^{+} \mathrm{IL}-17^{+}$ in D2 and D3 groups was significantly higher compared to the D1 group (7.53\% and $7.77 \%$ vs. $5.24 \%$ respectively). 
A
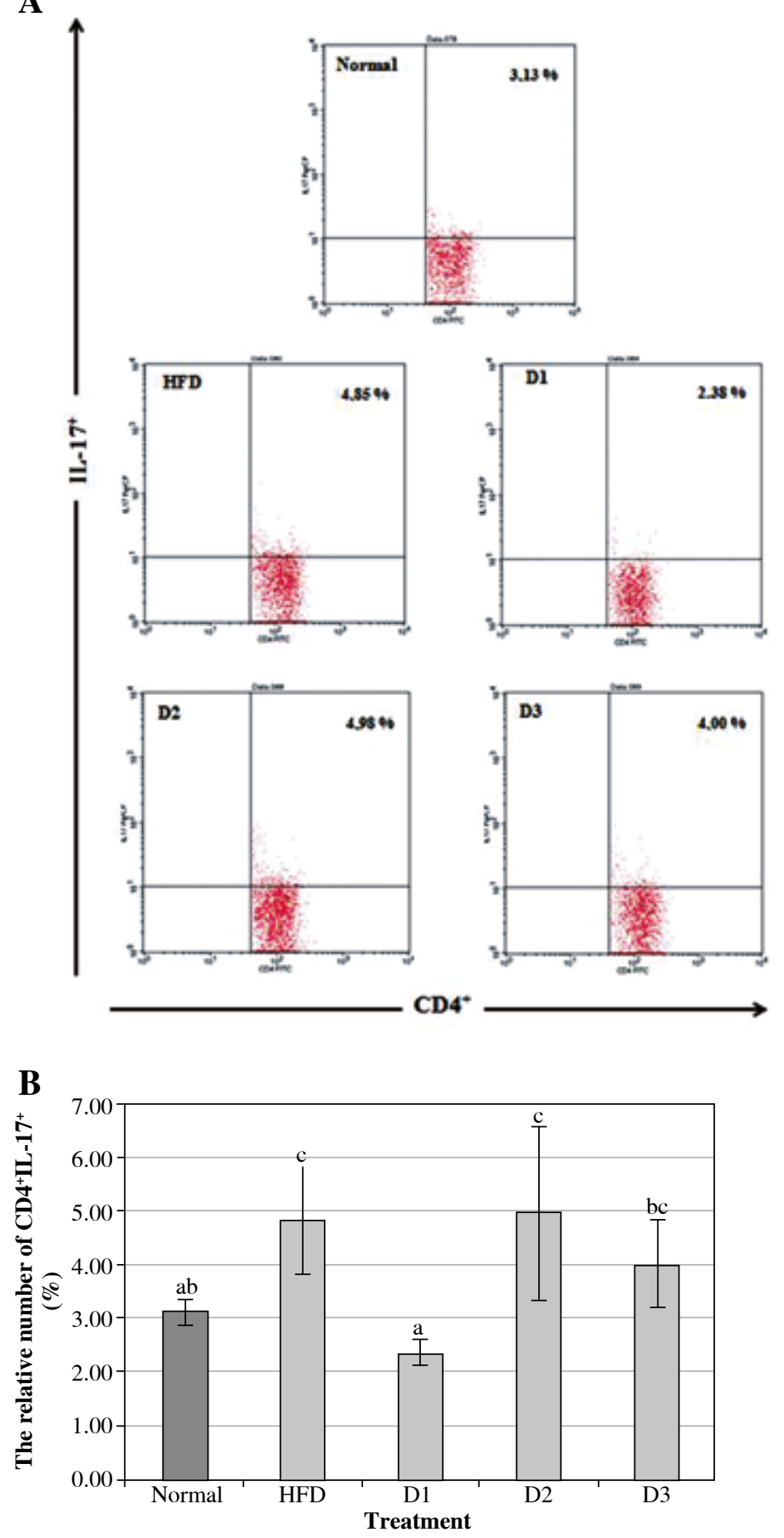

Fig. 1. The lowest dose of Agaricus blazei could inhibit the expression of IL-17 on CD-4 T-lymphocyte in vivo. A) The relative number of CD4 ${ }^{+} \mathrm{IL}-17^{+}$splenocytes after 12 weeks of treatment and analyzed by flow cytometry (normal - healthy control, HFD - high-fat diet, D1 - low dose of A. blazei [100 mg/kg BW], D2 - normal dose of A. blazei [200 mg/kg BW], and D3 high dose of $A$. blazei [400 mg/kg BW]). Data are mean of \pm SD values of 3 mice in each group. B) The bars are the calculation of the number CD4 T cells expressing positive IL-17 on the splenocytes of mice in vivo. It showed that A. blazei treatment at a dose of $100 \mathrm{mg} / \mathrm{kg} \mathrm{BW}$ (D1) has a smaller number of IL-17 in all doses of A. blazei treatments than the control group. Data are mean of \pm standard deviation values of three mice in each group with $p$-value $<0.05$. Different letters indicate a significant difference based on Tukey's high significant differences test at a 95\% significance level 

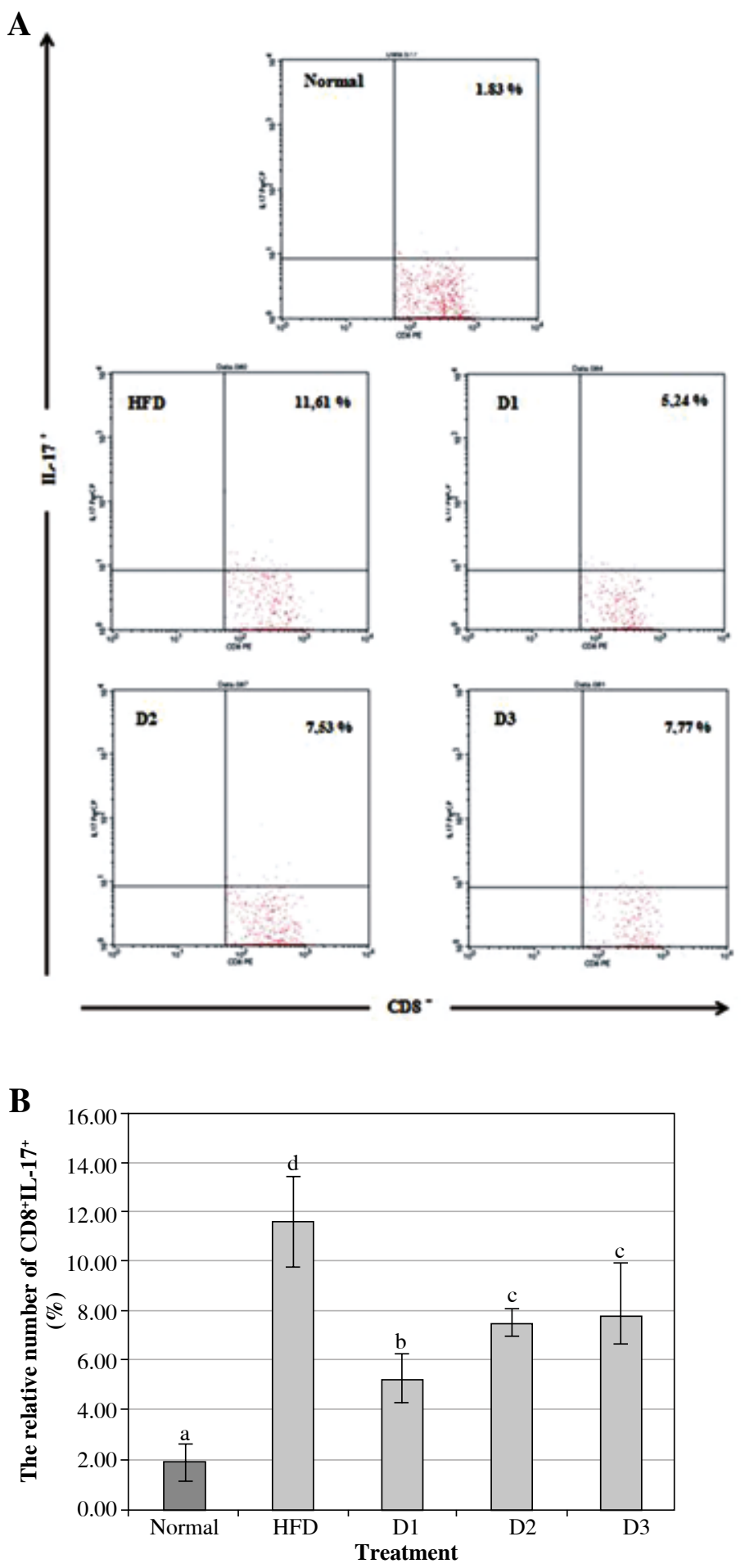

Fig. 2. Agaricus blazei at a dose of $100 \mathrm{mg} / \mathrm{kg}$ BW could decrease the expression of IL-17 on CD8 T-lymphocyte in vivo. A) The relative number of CD8 ${ }^{+} \mathrm{IL}-17^{+}$splenocytes after 12 weeks of treatment and analyzed by flow cytometry (normal healthy control, HFD - high-fat diet, D1 - low dose of A. blazei [100 mg/kg BW], D2 - normal dose of A. blazei [200 mg/kg BW], and D3 - high dose of A. blazei [400 mg/kg BW]). Data are mean of \pm SD values of 3 mice in each group. B) The bars are a calculation of the number of CD8 T cells expressing positive IL-17 on the splenocytes of mice in vivo. It showed that A. blazei treatment at a dose of $100 \mathrm{mg} / \mathrm{kg} \mathrm{BW}$ (D1) has a smaller number of IL-17 in all doses of A. blazei treatments than the control group. Data are mean of \pm standard deviation values of three mice in each group with $p$-value $<0.05$. Different letters indicate a significant difference based on Tukey's high significant differences test at a 95\% significance level 

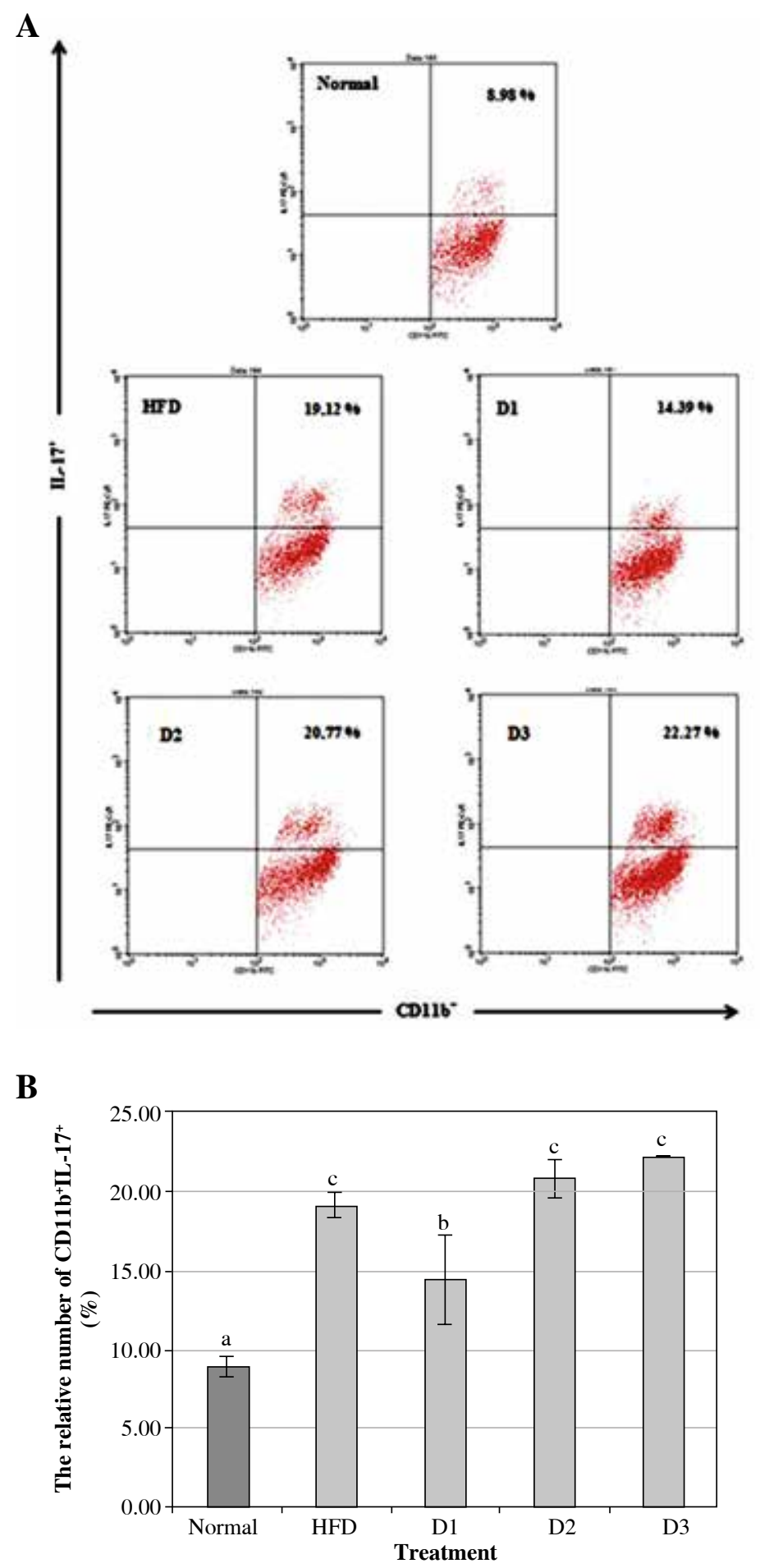

Fig. 3. Agaricus blazei modulates the expression of IL-17 on CD11b in vivo. A) The relative number of CD11b $\mathrm{I}^{+} \mathrm{LL}-17^{+}$ splenocytes after 12 weeks of treatment and analyzed by flow cytometry (normal = healthy control, HFD - high-fat diet, D1 - low dose of A. blazei [100 mg/kg BW], D2 - normal dose of A. blazei [200 mg/kg BW], and D3 - high dose of A. blazei $[400 \mathrm{mg} / \mathrm{kg} \mathrm{BW]}$ ). Data are mean of $\pm \mathrm{SD}$ values of 3 mice in each group. B) The bars are a calculation of the number of CD11b cells expressing positive IL-17 on the splenocytes of mice in vivo. It showed that A. blazei treatment at a dose of $100 \mathrm{mg} / \mathrm{kg} \mathrm{BW}$ (D1) has a smaller number of IL-17 in all doses of A. blazei treatments than the control group. Data are mean of \pm standard deviation values of three mice in each group with $p$-value $<0.05$. Different letters indicate a significant difference based on Tukey's high significant differences test at a 95\% significance level 
However, no significant difference was found in the level of CD8 ${ }^{+} \mathrm{IL}-17^{+}$between D2 and D3 groups compared with HFD treatment.

\section{Agaricus blazei is able to modulate the expression of IL-17 by leukocyte cells}

$\mathrm{CD} 11 \mathrm{~b}$ is a molecule which is expressed on the surface of many leukocytes including monocytes, neutrophils, NK cells, granulocytes and macrophages. This study revealed that the level of CD11 $\mathrm{b}^{+} \mathrm{IL}-17^{+}$in Balb/c mice with HFD is significantly increased compared with the healthy group (19.12\% vs. $8.98 \%)$. Furthermore, the level of CD $11 \mathrm{~b}^{+} \mathrm{IL}-17^{+}$A. blazei at a dose of $100 \mathrm{mg} / \mathrm{kg}$ BW is markedly reduced compared with HFD treatment $(14.39 \%$ vs. $20.77 \%)$. On the other hand, there is no significant difference in the level of CD $11 \mathrm{~b}^{+} \mathrm{IL}-17^{+}$at a dose of $200 \mathrm{mg} / \mathrm{kg} \mathrm{BW}$ (D2) and $400 \mathrm{mg} / \mathrm{kg} \mathrm{BW}$ (D3) compared with HFD treatment $(20.77 \%$ vs. $19.12 \%$, and $22.77 \%$ vs. $19.12 \%$ respectively). These data suggested that $A$. blaze $i$ is able to act as an immunomodulatory agent, where the optimal dose to decrease the level of $\mathrm{CD} 11 \mathrm{~b}^{+} \mathrm{IL}-17^{+}$is $100 \mathrm{mg} / \mathrm{kg} \mathrm{BW}$ (D1).

\section{Discussion}

In the present study, we assessed the expression of $\mathrm{CD} 4^{+} \mathrm{IL}-17^{+}$and $\mathrm{CD} 8^{+} \mathrm{IL}-17^{+}$in Balb/c mice with the atherosclerosis model induced by HFD treatment. We found that the level of CD4 $4^{+} \mathrm{IL}-17^{+}$and $\mathrm{CD} 8^{+} \mathrm{IL}-17^{+}$in the HFD group was markedly increased compared to the control group with standard feed. The increasing level of IL-17 indicates inflammation. Inflammation is a major cause of atherosclerosis which is present in all stages of atherosclerosis [12]. Inflammation plays an important role in the stability of the atherosclerotic plaque, which is a potential plaque to be a thrombogenic one [13].

In our model, Balb/c mice were treated with HFD to induce atherosclerosis. The results showed that mice with HFD treatment had a higher level of Lp-PLA2 compared with the control group (data not shown). Lipoprotein-Associated Phospholipase A2 (Lp-PLA2), also known as plasma platelet-activating factor acetyl hydrolase (PAF-AH plasma), is a $\mathrm{Ca}^{2+}$-independent phospholipase enzyme with a molecular weight of $50 \mathrm{kDa}$. This enzyme is mainly produced by macrophages, lymphocytes, and mast cells and is a subtype of the phospholipase A2 superfamily, which is a group of phospholipids hydrolyzing enzymes. Atherosclerotic plaques especially the lipid core and fibrous capsule macrophages in the rupture prone lesions express Lp-PLA2. Therefore, LpPLA2 can be used as a marker of plaque destabilization before rupture of the arterial plaque $[14,15]$.

Hyperlipidemia, hyperglycemia, smoking, oxidized low-density lipoprotein (ox-LDL) are able to activate vas- cular cell adhesion molecule 1 (VCAM-1), which causes endothelial cell dysfunction. VCAM-1 triggers the attachment of leukocytes, recruiting of monocytes, and migration of activated platelets to the endothelium. The monocytes then differentiate into macrophages which express scavenger receptors. Macrophages are identified as carriers of the immune system that eliminates a number of lipids through receptors and from foam cells, which can be fatty-streak lesions [16]. Binder et al. [17] and Lichtman et al. [18] reported that during this process $\mathrm{T}$ cells are also activated by ox-LDL, human leukocyte antigen (HLA), and other antigens. Activated $\mathrm{T}$ cell response increases inflammation by producing inflammatory mediators.

IL-17 is a pro-inflammatory cytokine that responds to the invasion of the immune system by inducing extracellular pathogen destruction of the extracellular matrix. Recently, $\mathrm{T}$ cells has been able to produce cytokines which appear not to be classified to Th1 and Th2 scheme but classified into Th17 cells. Since this study had been reported, T cells are differentiated into Th1, Th2, and Th17 cells [19]. It is also reported that IL-17 is produced by a type of hematopoietic cells, other than Th17, $\gamma \delta$ T cells, NK cells, macrophages, dendritic cells, neutrophils, and mast cells that rapidly produce IL-17 in response to proinflammatory cytokines [20]. Th1 and Th17 cells play a role in autoimmunity whereas the allergy response is related to $\mathrm{Th} 2$ cells [21].

Thus far, IL-17 has pro-atherogenic effects by inducing the production of cytokines, chemokines, and matrix metalloproteinases. IL-17 also stimulates the granulocytes colony stimulating factor (G-CSF) that mediates granulopoiesis and attracts immune cells. IL-17 induces apoptosis of endothelial cells and cardiomyocytes by activation of caspase-3 and caspase-9, and upregulation of Bax/Bcl-2, which causes damage to the endothelium. The atheroprotective effect appears to be mediated by the regulation of other cytokines (IFN- $\gamma$ decrease) and by inhibiting the expression of VCAM-1, a molecule that mediates the accumulation of monocytes and $\mathrm{T}$ cells in the lesions. The axis of IL-23-IL-17 is an important regulatory system that arises as a mediator of the innate and adaptive immune system [20].

It is well documented that there are 5 families of IL-17 receptors (IL-17R): IL-17RA - IL-17RE. IL-17 and IL-17F primarily bind to IL-17RA and IL-17 RC in the epithelial cells, vascular endothelium, and fibroblasts, then activate the transcription factor NFKB and mitogen-activated protein kinase (MAPKs). The pathway then induced the expression of a variation type of pro-inflammatory mediators such as TNF, IL-1, IL-6, chemokines (CXCL11, IL-8, CCL-2), MMP (MMP-1, MMP-3, MMP-9) and C-reactive protein (CRP) which causes inflammation and cell adhesion-making neutrophils, T cells, macrophages, and other types of immune cells [22]. This effect indicates that IL-17 plays a role in the progression of inflammation and host defense against bacterial infections and also in the stability of the atherosclerotic plaque and its complications [23]. 
It was also demonstrated that the level of cytokine IL-17 was significantly decreased in A. blazei treatment at a dose of $100 \mathrm{mg} / \mathrm{kg}$ BW compared to the HFD group. A. blazei has various bioactive compounds such as polysaccharides, proteoglycans, terpenoids, phenolic compounds, steroids, and lectins. $\beta$-glucan in A. blazei is a polysaccharide that is naturally contained in grains, yeast, bacteria, algae, and fungi. $\beta$-glucan is also known to have the ability as an antibacterial, antiviral agent, and an immunomodulator for prevention and treatment of various diseases [24].

Pranamuda et al. [25] reported that the immunomodulatory activity of $\beta$-glucan in lymphocyte proliferation in vitro can be observed using MTT assay method. The results showed that $\beta$-glucan extract was capable of inducing human lymphocyte proliferation in a dose-dependent manner. The highest level of lymphocyte proliferation by $\beta$-glucan was achieved at a concentration of $250 \mathrm{ppm}$. At this concentration, the stimulation index reached $106.9 \%$ or was 2.5 times higher than the control.

Another study by Queiroz et al. [26] stated that at a dose of $100 \mathrm{mg} / \mathrm{kg}, \beta$-glucan from Caripia montagnei is able to markedly decrease the inflammatory reaction in mice with the thioglycolate-induced peritonitis model. This anti-inflammatory reaction was explained by an increase in the IL-10 level, the anti-inflammatory cytokine concomitant with a reduction in IFN- $\gamma$, the pro-inflammatory cytokine. Jedinak et al. [27] also reported that $\beta$-glucan from mushroom Pleurotus ostreatus was able to suppress the level of pro-inflammatory cytokines by measuring the level of IFN- $\gamma$, IL-2, and IL-6. The results also showed the reduction of those pro-inflammatory cytokines from concanavalin A (ConA)-stimulated mouse splenocytes.

Interestingly, the level of pro-inflammatory cytokine IL-17 at a dose of $200 \mathrm{mg} / \mathrm{kg} \mathrm{BW}$ (D2) and $400 \mathrm{mg} / \mathrm{kg}$ BW (D3) was non-significantly different in CD4 $4^{+} \mathrm{IL}-17^{+}$ compared to HFD treatment and we found it was significantly higher than $\mathrm{D} 1$ treatment in $\mathrm{CD} 8^{+} \mathrm{IL}-17^{+}$. It can be explained that beside the positive effects, $\beta$-glucan in A. blazei also has undesirable effects. Tanriverdi et al. [28] demonstrated that at a certain concentration, $\beta$-glucan can induce an inflammatory reaction and granuloma formation. This pro-inflammatory action leads to the continuous effect which is manifested in the subsequent fatal multiple organ dysfunction syndrome (MODS).

The mechanism of $\beta$-glucan as an immunostimulatory agent can be explained by the binding of $\beta$-glucan to receptors of CR3 complement membranes in macrophages $[29,30]$. The binding of $\beta$-glucan to macrophages activates macrophages and cells to produce several cytokines to induce a specific immune response [31].

\section{Conclusions}

In summary, the results of the present study demonstrated that HFD treatment could induce atherosclerosis in Balb/C mice by the increasing level of Lp-PLA2. The administration of $A$. blaze $i$ extract at a dose of $100 \mathrm{mg} / \mathrm{kg}$ BW for 12 weeks significantly decreased the level of IL-17 compared to the HFD group. While the expression of IL-17 in the treatment of A. blazei at a dose of $200 \mathrm{mg} / \mathrm{kg}$ BW (D2) and $400 \mathrm{mg} / \mathrm{kg}$ BW (D3) was significantly increased. These results could explain that $\beta$-glucan in A. blazei may act as an immunomodulator in $\mathrm{Balb} / \mathrm{c}$ mice with atherosclerosis. However, A. blazei at a dose of $100 \mathrm{mg} / \mathrm{kg} \mathrm{BW}$ may be an optimal dose to minimize or prevent the damage from atherosclerosis. Although our investigations might provide some information for the possible use of A. blazei as an immunomodulator in atherosclerosis, further studies are necessary to determine the mechanism of its immunomodulatory action.

\section{Acknowledgements}

The authors would like to thank to Mr. Widodo Ph.D. Med. Sc. for careful reading and critical comments on this manuscript and also to all fellow researchers in the Animal Physiology Laboratory, University of Brawijaya, who provided much help in the process of this research.

\section{The authors declare no conflict of interest.}

\section{References}

1. Hansson GK, Libby P (2006): The immune response in atherosclerosis: a double edged sword. Nat Rev Immunol 6: 508-19,

2. Entin-Meer M, Afek A, George J (2009): Regulatory T-cells, FoxP3 and atherosclerosis. Adv Exp Med Biol 665: 106-114.

3. Christiakov DA, Sobenin IA, Orekhov AN (2013): Regulatory $\mathrm{T}$ cells in atherosclerosis and strategies to induce the endogenous atheroprotective immune response. Immunol Lett 151: 10-22.

4. Weintraub HS (2008): Identifying the Vulnerable Patient with Rupture-Prone Plaque. Am J Cardiol 101: 3F-10F.

5. Epps KC, Wilensky RL (2011): Lp-PLA2-A Novel Risk Factor for High risk Coronary and Carotid Artery Disease. J Intern Med 269: 94-106.

6. Gisterí A, Robertson AK, Andersson J, et al. (2013): TGF $\beta$ signaling in $\mathrm{T}$ cells promotes stabilization of atherosclerosis plaque through IL-17. Sci Transl Med 5: 196.

7. Dong C (2008). TH17 cells in development: an updated view of their molecular identity and genetic programming. Nat Rev Immunol 5: 337-348.

8. Li C, Ha T, Kelley J, et al. (2004): Modulating Toll-like receptor mediated signaling by (1-3)-beta-D-glucan rapidly induces cardioprotection. Cardiovasc Res 61: 538-547. 
9. Kim YW, Kim KH, Choi HJ, Lee DS (2005): Anti-diabetic activity of betaglucans and their enzymatically hydrolyzed oligosaccharides from Agaricus blazei. Biotechnol Lett 27: 483-487.

10. Reyna-Villasmil N, Bermúdez-Pirela V, Mengual-Moreno E, et al. (2007): Oat-derived beta-glucan significantly improves HDLC and diminishes LDLC and non-HDL cholesterol in overweight individuals with mild hypercholesterolemia. Am J Ther 14: 203-212.

11. Roupas P, Keogh J, Noakes M, et al. (2012): The role of edible mushrooms in health: Evaluation of the evidence. J Funct Foods 4: 687-709.

12. Libby $\mathrm{P}$ (2002): Inflammation in Atherosclerosis. Nature 420: 868-874.

13. Hansson GK (2005): Inflammation, atherosclerosis and coronary artery disease. N Engl J Med 352: 1685-1695.

14. Sudhir K (2005): Clinical review: lipoprotein-associated phospholipase A2, a novel inflammatory biomarker and independent risk predictor for cardiovascular disease. J Clin Endo Metab 90: 3100-3105.

15. Sudhir K (2006): Vascular Health and Risk Management. Lipoprotein-associated phospholipase A2, vascular inflammation and cardiovascular risk prediction. Vasc Health Risk Manag 2: 153-156.

16. Cybulsky MI, Gimbrone MA Jr (1991): Endothelial expression of a mononuclear leukocyte adhesion molecule, in rabbit aortic endothelium. Science 251: 788-791.

17. Binder CJ, Chang MK, Shaw PX, et al. (2002): Innate and acquired immunity in atherogenesis. Nat Med 8: 1218-1226.

18. Lichtman AH, Binder CJ, Tsimikas S, Witztum JL (2013): Adaptive immunity in atherogenesis: new insights and therapeutic approaches. J Clin Invest 123: 27-36.

19. Miossec P, Korn T, Kuchroo VK (2009): Interleukin-17 and type 17 helper T cells. N Engl J Med 361: 888-898.

20. Liuzzo G, Trotta F, Pedicino D (2013): Interleukin-17 in atherosclerosis and cardiovascular disease: the good, the bad and the unknown. Eur Heart J 34: 556-559.

21. Pober JS (2011): Interleukin-17 and atherosclerotic vascular disease. Arterioscler Thromb Vasc Biol 31: 1465-1466.

22. Gaffen SL (2009): Structure and signalling in the IL-17 receptor family. Nat Rev Immunol 8: 556-567.

23. Su SA, Ma H, Shen L, et al. (2013): Interleukin-17 and acute coronary syndrome. J Zhejiang Univ Sci B 14: 664-669.

24. Hozova B, Kuniak L, Kelemenova B (2004): Application of $\beta$-D-Glucans Isolated from Mushrooms Pleurotus ostreatus (Pleuran) and Lentinus edodes (Lentinan) for Increasing the Bioactivity of Yoghurts. Czech J Food Sci 22: 204-214.

25. Pranamuda H, Giarni R, Pradana A, et al. (2012): Aplikasi beta glukan sebagai bahan berkhasiat imunomodulator dan antikanker. Prosiding InSINas KO-70-73.

26. Queiroz LS, Nascimento MS, Cruz AK et al. (2010): Glucans from the Caripia montagnei mushroom present anti-inflammatory activity. Int Immunopharmacol 10: 34-42.

27. Jedinak A, Shailesh D, Qing-li W, et al. (2011): Anti-inflammatory activity of edible oyster mushroom is mediated through the inhibition of NF- $\mathrm{KB}$ and AP-1 signaling. Nutr J 10: 52 .

28. Tanriverdi P, Yuksel, BC, Rasa K, et al. (2005): The effects of selective nitric oxide synthase blocker on survival, mesenteric blood flow and multiple organ failure induced by zymosan. J Surg Res 124: 67-73.
29. Sarangi I, Ghosh D, Bhutia SK, et al. (2006): Anti-tumor and Immunomodulating Effects of Pleurotus ostreatus Mycelia derived Proteoglycans. Int J Immunopharmacol 6: 1287-1297.

30. Radji M (2010): Imunologi dan Virologi. Cetakan pertama. Jakarta: PT ISFI Penerbitan.

31. Rop O, Mlcek J, Jurikova T (2009): Beta-glucans in Higher Fungi and Their Health Effect. Article Nutrition Rev 67: 624-631. 